\title{
Construction of Online Agricultural Product Consumption Demand Analysis Model Based on Data Mining Technology
}

\author{
Xin Yi \\ Digital Business Academy, Beijing Information Technology College, Beijing 100018, China \\ Correspondence should be addressed to Xin Yi; yix@bitc.edu.cn
}

Received 29 December 2021; Revised 16 January 2022; Accepted 25 January 2022; Published 10 February 2022

Academic Editor: Qiangyi Li

Copyright (c) 2022 Xin Yi. This is an open access article distributed under the Creative Commons Attribution License, which permits unrestricted use, distribution, and reproduction in any medium, provided the original work is properly cited.

\begin{abstract}
The traditional offline marketing mode of agricultural products was relatively single and difficult to adapt to the effective communication between agricultural and commercial enterprises and customers under the new situation, while the coordination between online agricultural products marketing management and customers' consumption needs was not enough. Therefore, this paper puts forward the research on the construction of online agricultural product consumption demand analysis model based on data mining technology. Based on the supply-demand relationship between agricultural and commercial enterprises and consumers, this paper analyzed consumers and their demand behavior for agricultural products and gave an evaluation model of customers' consumption demand for agricultural products. Using data mining technology, this paper made a cluster analysis on the characteristics of consumer demand behavior and established the mapping relationship between agricultural products and consumer demand. Then, the online consumption demand prediction and analysis model of agricultural products was put forward. Finally, the performance of demand forecasting model based on data classification was analyzed. The empirical results showed that the model proposed in this paper can better predict and analyze the consumption demand behavior of online agricultural products and had certain feasibility and effectiveness. The online consumption demand analysis model proposed in this paper played a positive role in improving the marketing management level of agricultural products.
\end{abstract}

\section{Introduction}

With the rapid development of Internet and information technology, the e-commerce industry has been rapidly improved. Among them, the agricultural product market has gradually changed from offline sales to online operation, which not only accelerates the circulation speed of agricultural products, but also changes the traditional management mode of agricultural products $[1,2]$. Online marketing promotes the communication between farmers and consumers, reduces the intermediate sales links of agricultural products, effectively widens the circulation channels of agricultural products, and makes the sales of agricultural products no longer affected by regional, social, and transportation factors. At the same time, consumers can buy agricultural products online to meet their demand wishes, stimulate consumption growth, and promote economic development.
In recent years, most agricultural and commercial enterprises have used the Internet and information technology to reform the business model of agricultural products through the combination of traditional sales and modern marketing based on the original offline marketing model. At present, most agricultural products have adopted the mode of online sales and service for operation and management [3]. Customers can not only buy agricultural products through traditional physical stores and online methods, but also integrate consumers into the online and offline agricultural product service management platform to respond to customer needs in real time through various ways. Online marketing management and services usually focus on consumer demand behavior and provide customers with consumption experience through different Internet and information platforms. Therefore, agricultural and commercial enterprises need to change from the traditional operation and management mode focusing on the 
production of agricultural products to the modern operation and management mode focusing on consumer demand, to provide consumers with accurate agricultural product demand services and efficient dynamic management response mechanism.

Although the e-commerce industry has promoted the reform of the management mode of agricultural products, there are still some problems in the process of online sales and service of agricultural products [4]. For example, the immature marketing model of online agricultural products may be difficult to win the trust of customers, and consumers may have some doubts about the quality and after-sales service of agricultural products sold online. Because the online agricultural product marketing is in the primary stage, there are many urgent problems to be solved in the online sales and service management. Therefore, how to manage the online agricultural product marketing model is the main problem that agricultural and commercial enterprises and operators need to study.

\section{Related Works}

Most of the foreign researches on the marketing model of agricultural products focus on the supply chain management of agricultural products, mainly focusing on the generation, operation and management mode of agricultural products, supply and marketing relationship, production, marketing, logistics, and service management of agricultural products. Some scholars conducted a questionnaire survey on consumers' demand standards and purchase intention of online agricultural products and carried out research on consumers' rational consumption behavior and planned consumption behavior [5]. The results show that planned consumption behavior can better explain consumers' purchase intention of agricultural products.

Some people have also studied the alliance management mode adopted by agricultural and commercial enterprises. The results show that the management of agricultural products through a unified logistics service platform and inventory management platform will greatly promote the circulation speed and service level of agricultural products [6]. The agricultural and commercial enterprise management service platform provided through the Internet and information technology not only facilitates consumers to buy required agricultural products, but also provides a reference for agricultural and commercial enterprises to further understand consumers' demand information and formulate effective marketing strategies.

In addition, some scholars have found that the development of the Internet provides more opportunities for agricultural products trading, and the use of e-commerce platform can effectively solve the unity between the production and supply of agricultural and commercial enterprises and the demand of consumers for agricultural products [7]. From the analysis of many e-commerce product marketing cases, it can be found that the circulation mode of traditional agricultural products has been impacted by the marketing mode of modern e-commerce agricultural products, and a new relationship between supply and demand has begun to appear $[8,9]$. At the same time, agricultural and commercial enterprises can truly realize the scale operation, information interaction, and efficient service of agricultural products only through the e-commerce platform.

Because the online sales modes of different types of products have their own characteristics, for the online sales of agricultural products, the factors affecting the online marketing of agricultural products also have certain characteristics. At present, in the research on the online consumption demand of agricultural products, most scholars study the demand behavior of consumers from the perspectives of business reputation, the architecture of online platform, logistics services, and customer concept and rarely build the online consumption demand prediction and analysis model by data mining and information extraction of online transaction information, which is used to study the law of consumers' demand for agricultural products [10]. Because agricultural products are different from other online sales products, people's online consumption demand expectation and online management and service of agricultural products may become factors affecting customers' purchase intention of agricultural products. Therefore, this paper proposes the research on the construction of online agricultural product consumption demand analysis model based on data mining technology, which can not only solve the problems of online agricultural product sales management and service to a certain extent, but also provide a reference for enterprises to further understand the potential agricultural product consumption demand market and customer willingness.

\section{Consumer Demand Behavior and Its Analysis}

\subsection{Supply and Demand Relationship between Enterprises and} Consumers. In order to broaden the online consumer demand market for agricultural products, enterprises can not only strengthen the operation and management of agricultural products, but also provide consumers with personalized services and commodity trading channels by using various information means and Internet technology and through the interactive platform between enterprises and consumers.

The supply-demand relationship between enterprises and consumers is mainly used to describe a behavioral relationship formed between enterprises and consumers through online sales, market competition, technical support, and so on. This supply-demand relationship can not only provide data services for enterprise operation and management, but also provide reference for consumers' agricultural products services launched by enterprises [11]. Using the supply-demand relationship platform between enterprises and consumers can not only stabilize the relationship between enterprises and consumers, improve the sales efficiency of agricultural products, and reduce the sales links and costs of enterprises, but also through the communication between enterprises and customers, improve consumers' satisfaction with agricultural products and services provided by enterprises and enhance consumers' trust in enterprise products and services. The 
supply-demand relationship between enterprises and consumers plays a win-win role for both enterprise operators and consumers.

As shown in Figure 1, the supply-demand relationship management platform between enterprises and consumers is divided into three parts: management function platform, analysis function platform, and interactive function platform.

The management function platform is used to manage the whole business process, mainly including the integrated management of sales function module, business function module, and consumer service function module. In addition, the management function platform also involves consumer after-sales service management, front-end and back-end integrated management, and other functions.

The analysis function platform is mainly used to analyze and process the marketing process. According to the information transmitted between the management function platform and the interactive platform, the platform adopts the business intelligence analysis method based on data analysis and mining technology to obtain the business decision-making basis required by the enterprise. The analysis function platform mainly includes consumer market analysis, marketing model analysis, consumer psychological analysis, consumer change analysis, enterprise marketing risk analysis, consumption cycle analysis, etc.

The interactive function platform is mainly used to manage business interaction behavior and realize communication and exchange between enterprises, customer service and customers through network trading platform, thirdparty service platform, e-mail, and telephone. From the supply-demand relationship structure between enterprises and consumers, its main tasks include management, analysis, and interaction. Moreover, the management, analysis, and interaction tasks are mainly completed through the management function layer, analysis function layer, and interaction function layer of the supply-demand relationship platform.

In order to effectively implement various functions of the supply-demand relationship platform, it is necessary to integrate consumption data [12]. Therefore, through the interactive function provided by the supply-demand relationship platform, the consumption data is input into the enterprise data management database, and then the data mining technology is used to extract relevant data information from the enterprise database, to provide support for enterprises to make marketing decisions. The overall implementation process of the supply and demand relationship platform between enterprises and customers is shown in Figure 2.

3.2. Consumer Behavior Analysis. Consumer behavior analysis is to establish a customer consumption behavior model based on the analysis of the consumption information provided by the supply-demand relationship platform between operators and consumers. Using this model to deeply analyze the commodity trading process can not only explore the behavior law of consumers' online commodity trading and interaction, but also help enterprises to deepen their understanding of customers' consumption behavior [13]. In addition, the analysis of consumption behavior can further strengthen the online service function of enterprises and provide basis for customers to improve consumption structure and consumption level.

By analyzing the consumption behavior, we can expand the new potential consumption market on the premise of ensuring the existing customer consumption market and enhance the marketing position of enterprises by constantly improving the business model and providing high-quality customer service. The results of consumer behavior analysis are very important to further improve the management concept and expand the consumer demand market and provide decision-making basis for enterprises to determine the operation mode and enhance their online trading ability. In addition, by analyzing consumer behavior, we can not only grasp the purchase intention and transaction behavior of different customer groups in real time, but also promote businesses to dynamically adjust marketing methods or strategies and increase business profits. For example, agricultural product operators can provide corresponding affordable packages for different categories of consumer groups according to the online consumption behavior analysis report, to expand the consumption demand market of agricultural products [14]. In addition, agricultural producers can customize the required agricultural products for different types of customers according to the results of consumer demand analysis, to meet the needs and aspirations of consumers.

Compared with the analysis function contained in the supply-demand relationship platform, by analyzing consumption behavior, we can master and track customers' consumption demand behavior in many aspects. Therefore, the consumption behavior analysis model can not only provide an effective reference for enterprises to promote agricultural products to appropriate consumers, but also provide support for the improvement of agricultural products production and commercial services in the future. As shown in Figure 3, it shows the relationship between the analysis function provided by the supply-demand relationship platform and the consumption behavior analysis model.

3.3. Supply and Demand Relationship Model. The supplydemand relationship model is mainly used to describe the transaction behavior response function and consumer demand evaluation function. The transaction behavior response model mainly reflects the response of merchants to market transaction behavior and is used to monitor the marketing process of products. Merchants can grasp the characteristics of different consumer groups by using the consumption behavior analysis results and then use the cluster analysis method to classify different consumer groups, to find potential consumer objects for operators, and provide help and guidance for enterprise business activities through the transaction behavior response model [15]. 


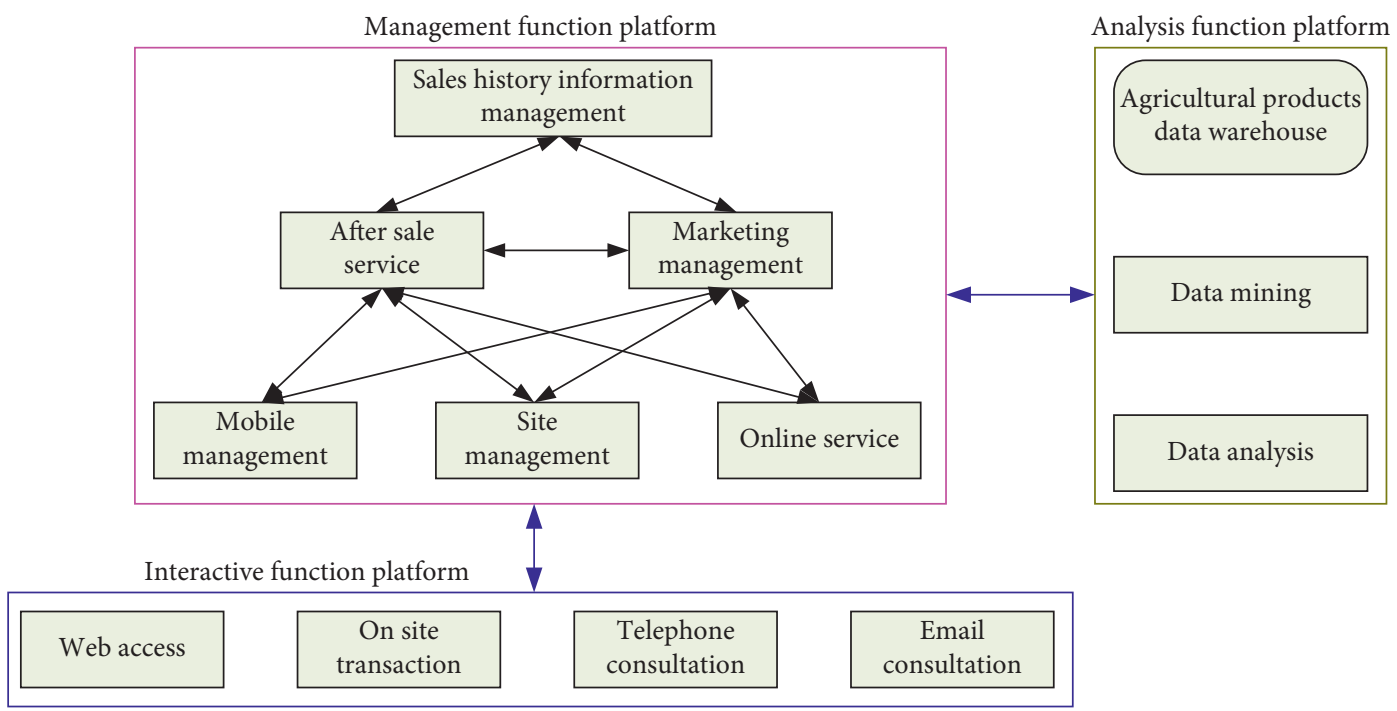

FIGURE 1: Supply and demand relationship management and the relationship between functional platforms.

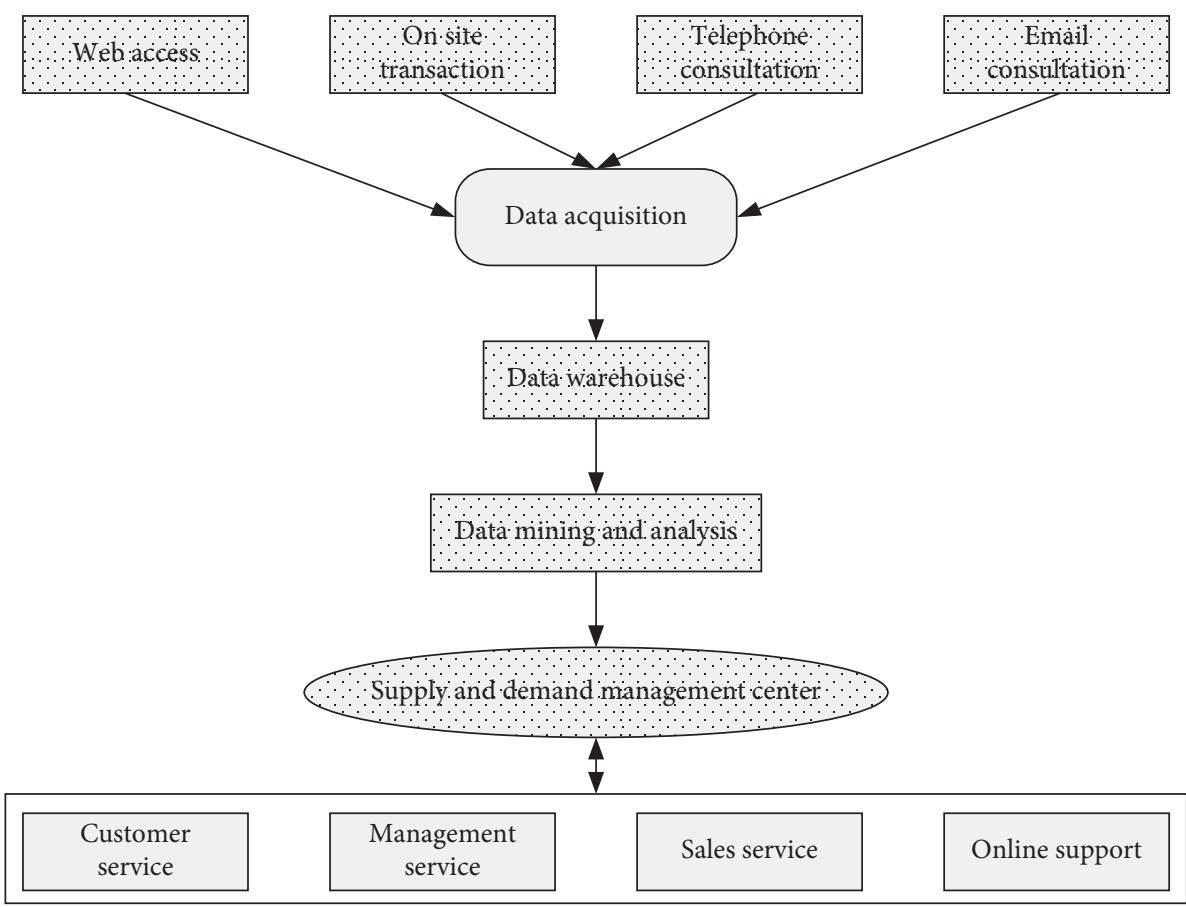

FIGURE 2: The overall implementation process of the supply and demand relationship platform between enterprises and customers.

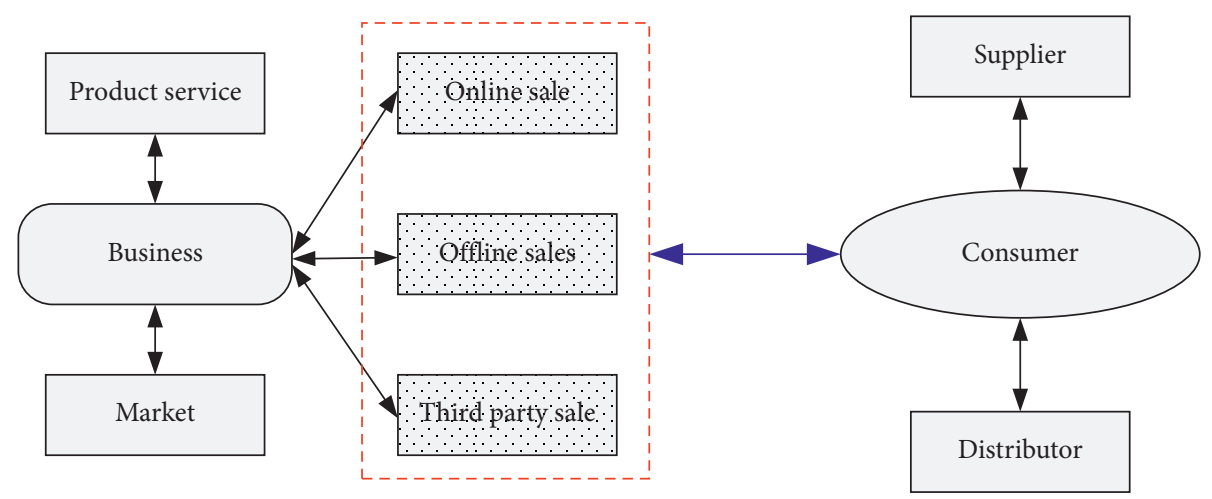

FIGURE 3: The relationship between the analysis function provided by the supply-demand relationship platform and the consumption behavior analysis model. 
Consumer demand evaluation is very important for the impact of merchants' product sales and benefits. Therefore, the establishment of a scientific consumer demand evaluation model can not only objectively reflect consumers' demand for products, but also effectively improve merchants' operation and management level. The consumer demand evaluation model can effectively predict consumers' online purchase tendency by describing consumers' purchase intention of different commodities and the law of their trading activities. Businesses analyze customers' consumption behavior and its change law according to consumption demand and evaluation data and formulate corresponding strategies to increase consumers' demand level and ability. The consumption demand evaluation model is shown in Figure 4.

\section{Construction of the Consumption Demand Analysis Model Based on Data Mining}

4.1. Concept and Method of Data Mining. Data mining mainly extracts relevant feature information through data processing and analysis, to provide reference basis for making relevant decisions. In the field of e-commerce application, using data mining technology can extract valuable feature information from different business data and select the features through data conversion processing or with the help of correlation analysis model, to provide reference for businesses to make decisions. Data mining should take the actual data as the processing object and the relevant needs of the industry as the background, to provide help for making scientific decisions.

The application of data mining technology in the field of e-commerce can help businesses understand and master the product demand and purchase intention of different consumer groups from the data analysis results and then tap the potential customer market through classified push products and flexible publicity, to improve the click through rate of customers to the products launched by merchants. Based on the statistics of customers' online access, consultation, and evaluation of stores, the potential consumption demand is mined through data analysis and fusion. At the same time, through data processing and analysis, the feedback results of customers' satisfaction with the quality of goods or services launched by businesses can not only provide decisionmaking basis for businesses to improve their products and services, but also meet the consumer needs expected by customers. In addition, applying data mining technology to the field of e-commerce can expand the consumer market and increase benefits for businesses by extracting valuable business information.

Choosing appropriate data mining methods is very important for establishing an effective online consumption demand analysis model of agricultural products. The goal of consumer demand analysis is not only to obtain consumer satisfaction feedback on enterprise marketing products and services, but also to provide reference for enterprises to further adjust marketing strategies and improve service management level [16]. Therefore, the supervised learning method can be adopted, and different algorithms can be selected by setting the expected target value and according to the data type of the target variable. For example, the discrete target variable value can be obtained by selecting the classification algorithm, and the continuous target variable value can be obtained by selecting the regression analysis method. If the results obtained by the data mining method are not to obtain the expected target value, but to classify the information through data subdivision processing, the cluster analysis method based on unsupervised learning should be adopted. In order to further analyze the similarity of data and its categories, a density estimation algorithm based on unsupervised learning is needed.

The data mining method needs to preprocess the obtained data in advance, obtain the required data information through feature extraction, and then select the appropriate algorithm to build the model. To establish a consumption demand analysis model based on data mining technology, it is generally necessary to continuously analyze, verify and optimize the parameters of the obtained data, and determine whether the algorithm is appropriate through the model execution results. Data mining mainly obtains the potential laws of things through the analysis, judgment, and extraction of relevant data. The application of data mining technology in the field of e-commerce mainly involves data collection, data analysis, feature extraction, model construction, and model performance test.

Generally, we need to obtain relevant data and eigenvalues from consumer demand information and target expectations. In terms of data collection, the source data information used to obtain the target expected value is extracted according to the consumption demand information, and the data is analyzed and processed from the aspects of data content, data attributes, data sources, etc. Data collection mainly obtains data through merchant customer interaction platform, sharing platform, and third-party platform. Through data analysis, processing, and feature extraction, for incomplete data information or abnormal data, generally, the data should be screened through mathematical statistics, principal component analysis, and clustering to mine the change trend of data or find abnormal data. Through data cleaning or other preprocessing, mine the data information required for modeling. In the aspect of model construction, starting from the application of consumption demand analysis model, appropriate data mining methods are used to optimize and adjust the model parameters, to build an analysis model that can serve online agricultural product sales and service. In the aspect of model performance test, it mainly judges whether the constructed model can be effectively applied. The model based on supervised learning method mainly uses the test set data samples to generate the confusion matrix and then comprehensively analyzes the performance of the model through the relevant indicators such as the accuracy and recall of the model, to judge the feasibility and effectiveness of the model.

4.2. User Demand Analysis Based on Feature Clustering. Extracting the characteristic keywords of relevant commodities from the consumer demand information for 


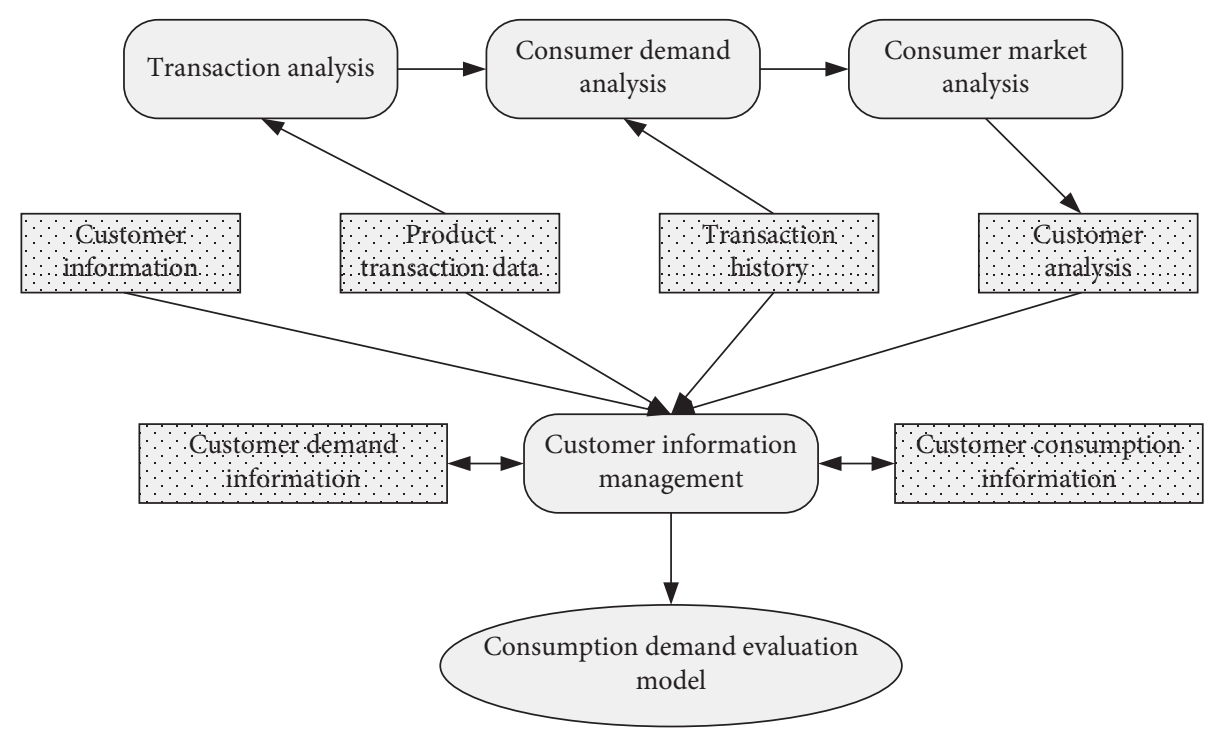

FIgURE 4: Construction process of the consumption demand evaluation model.

agricultural products can establish the mapping relationship between the characteristic keywords of agricultural products and consumer demand behavior and thus construct the index system of consumer demand for agricultural products. By analyzing customers' demand behavior for different agricultural products, we can explore the law of consumption demand behavior.

The mapping relationship between agricultural product characteristic keywords and consumption demand behavior can reflect the degree of agricultural product suppliers' mastery of customer consumption demand process. In the process of consumer demand behavior of agricultural products, customers mainly pay more attention to the quality, price, and origin of agricultural products. Customers feedback the consumption demand characteristics of agricultural products to customer service through the interactive function of the supply-demand relationship platform and feedback the consumption demand behavior information to agricultural product manufacturers and suppliers, so that enterprises can respond to customers' consumption demand behavior in time for corresponding strategy adjustment. In addition, using the mapping relationship between the characteristics of agricultural products and consumer demand behavior can enable businesses to truly understand and master customers' demand wishes and requirements for agricultural products [17]. Businesses classify and summarize customers' consumption groups and demand behavior through data mining and closely connect customer demand with the supply of agricultural products. Therefore, in-depth mining of online agricultural product consumption demand information is the key for enterprises to understand and identify customer consumption behavior. The mapping relationship between agricultural products and consumer demand obtained by product feature clustering is shown in Figure 5.

By collecting the online consumption demand information of agricultural products, using the data mining method to cluster the consumption data of agricultural products, and then according to the mapping relationship between the characteristics of agricultural products and customer consumption demand, the consumption demand law of agricultural products can be obtained. Through the cluster analysis of consumer demand behavior, we can know the demand factors of customers for agricultural products. As shown in Table 1, the demand elements of customers for online agricultural products are listed.

4.3. Construction of the Demand Forecasting Model. Using the data of customers' consumption demand for agricultural products obtained from the supply-demand relationship platform, the prediction and analysis model of consumption demand for agricultural products can be constructed. Due to the large amount of online agricultural product consumption demand information and different data types, the corresponding functional modules need to be established when constructing the consumption demand prediction and analysis model.

The consumption expectation prediction function mainly predicts the consumption trend in the future according to the past information of online consumption demand [18]. Because consumer demand behavior may have a certain time periodicity, therefore, exponential smoothing method can be used to predict consumers' expected behavior on agricultural products.

For each test set sample collected, it is necessary to calculate the marketing volume of the sample in the past three cycles and predict the consumption expectation of each test set sample. In order to predict the online consumption demand of a certain type of agricultural products, the test sample set of each type of agricultural products can be used to calculate the actual sales volume of the agricultural products in the past period and then predict the future consumption demand of the agricultural products.

According to the samples of each type of agricultural products, the actual sales volume of the product in the past 


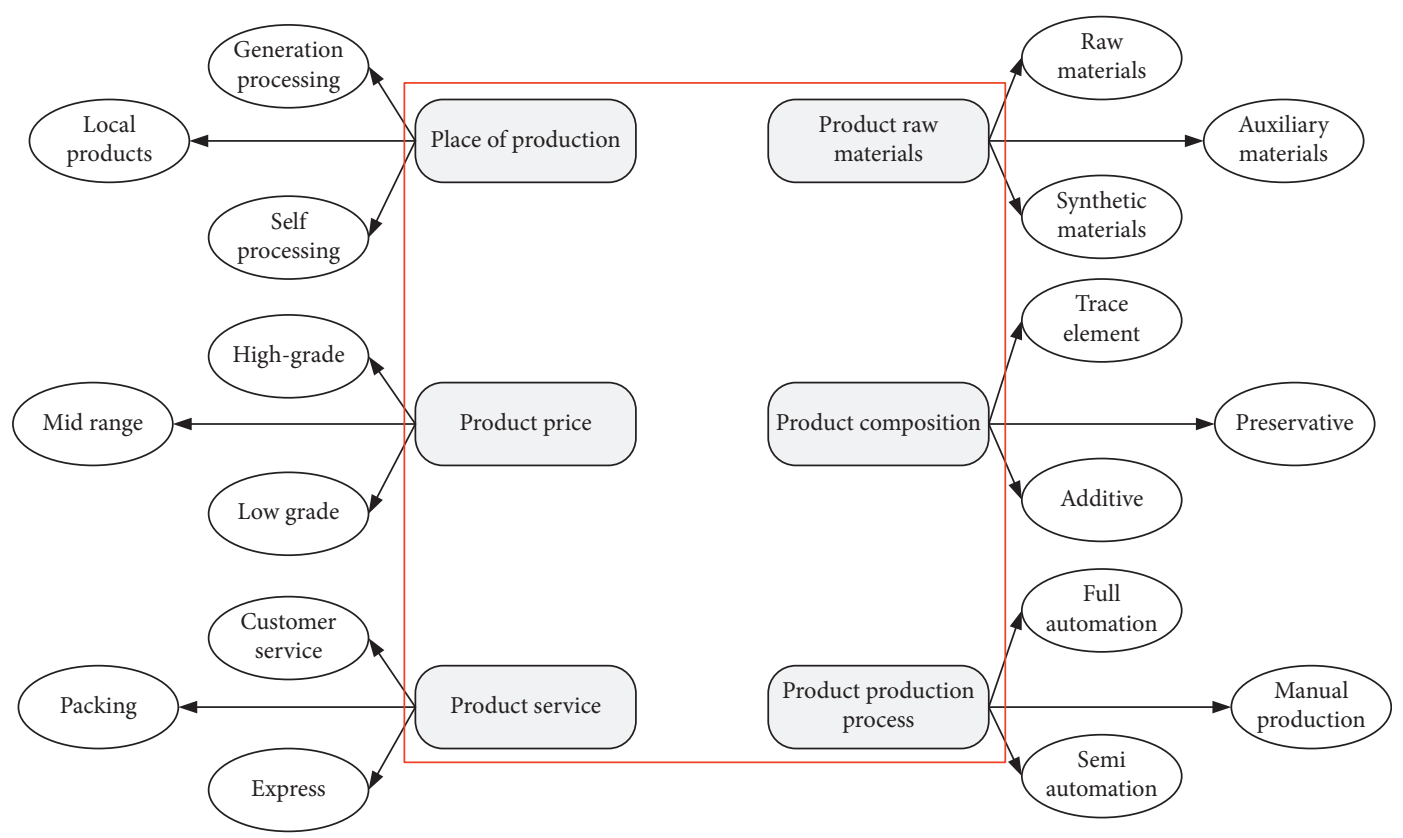

FIGURE 5: Mapping relationship between agricultural products and consumer demand.

TABLE 1: Elements of consumer demand for agricultural products.

\begin{tabular}{lcc}
\hline Primary element & Secondary element & Tertiary element \\
\hline Product price & High-grade & - \\
& Mid-range & - \\
& Low-grade & Online service \\
& Offline service \\
& Packing method & Express speed \\
Product service & Express & Fine packaging \\
& Packing & Ordinary packaging \\
\hline & Raw materials & - \\
Product raw materials & Synthetic materials & - \\
& Auxiliary materials & - \\
\hline \multirow{2}{*}{ Place of production } & Local products & - \\
\end{tabular}

cycle can be calculated, and the calculation formula is as follows:

$$
\begin{aligned}
& M_{t}=2 Y_{t 1}-Y_{t 2}, \\
& N_{t}=\frac{\varepsilon}{1-\varepsilon}\left(Y_{t 1}-Y_{t 2}\right),
\end{aligned}
$$

where $Y_{t 1}$ represents the actual sales volume of such agricultural products in the past cycle, $Y_{t 2}$ shows the actual sales volume of such agricultural products in the past two cycles, $M_{t}$ denotes the actual sales of such agricultural products in the past week, $N_{t}$ denotes the actual sales loss of such agricultural products in the past week, and $\mathcal{E}$ is weight coefficient.

$$
\begin{aligned}
Y_{t 2} & =\varepsilon Y_{t 1}+(1-\varepsilon) Y_{(t-1) 2} \\
W_{t+1} & =M_{t}+N_{t}
\end{aligned}
$$

where $Y_{(t-1) 2}$ is the actual sales volume of such agricultural products before the past cycle and $W_{t+1}$ indicates the expected sales volume of such agricultural products in the next cycle.

Because there are many electronic commerce enterprises of agricultural products, there are many types of online commodities launched by merchants, and there are great differences in the types, prices, and origin of agricultural products. Therefore, consumers' consumption demand and influencing factors for different agricultural products are also different. Considering that the same influencing factors may lead to differences in customers' consumption demand for different agricultural products, it is usually difficult to use a single model to predict the consumption demand behavior of all agricultural products. Therefore, we can carry out cluster analysis on commodities according to different factors such as the use, origin, and price of agricultural 
products and train different types of consumer demand datasets, to obtain a better prediction model.

According to the characteristics of consumer demand information, clustering method can be used to classify the obtained data. This method needs to determine different feature keywords from the dataset, generate several data clusters according to different features, and then classify the test set samples into different data clusters according to the principle of nearest distance [19]. Then, update the coordinate value of the data cluster, classify different test set samples according to the above method until the coordinate value of the data cluster remains unchanged, and finally get the clustering results of the test set samples. When classifying different test sample sets, because the online sales mode, consumer demand mode, sales price, and sales volume of similar agricultural products may be similar, the test sample set can be trained according to the category of agricultural products, to train a better online consumption demand prediction and analysis model. The test set sample training method based on data classification is used to train the model based on data classification. Compared with other training methods, it can reduce the complexity of model training.

\section{Model Performance and Empirical Analysis}

5.1. Performance Analysis of the Demand Forecasting Model Based on Data Classification. The performance analysis and evaluation of the model is mainly based on the error matrix generated by the test set, and the accuracy, recall, and $F_{1}$ score of the model are calculated through the error matrix, to analyze and evaluate the performance and effect of the model [8-10]. As shown in Table 2, the columns in the error matrix represent the predicted value and the rows represent the actual value.

In Table 2, TT means the correct sales volume of agricultural products predicted by the consumption demand model, TF represents the sales volume of agricultural products predicted incorrectly by the consumer demand model, FT indicates the quantity of agricultural products not sold, and FF means the number of unsold agricultural products predicted by the model.

The accuracy of the model is mainly expressed by the ratio of the number of test samples accurately predicted by the model to the total number of test samples. It is used to describe the accuracy of model prediction. TP and TN, respectively, represent the number of two test samples on the diagonal of the error matrix. According to the accuracy calculation formula of the model, the greater the sum of the number of test samples on the main diagonal, the higher the accuracy of the model. The accuracy calculation formula of the model is as follows:

$$
A c=\frac{\mathrm{TT}+\mathrm{FF}}{\mathrm{TT}+\mathrm{FF}+\mathrm{TF}+\mathrm{FT}} .
$$

The precision of the model is mainly expressed by the ratio of the number of correctly predicted positive test samples to the total number of predicted positive test samples, which is used to describe the precision of predicting positive test samples. The precision calculation formula of the model is as follows:

$$
P r=\frac{\mathrm{TT}}{\mathrm{TT}+\mathrm{TF}} .
$$

The recall rate of the model is mainly expressed by accurately predicting the ratio of the number of positive test samples to the total number of positive test samples, which is used to describe the coverage of the model. The recall rate of the model is calculated as follows:

$$
R e=\frac{\mathrm{TT}}{\mathrm{TT}+\mathrm{FT}} .
$$

The performance of the model is mainly evaluated by the accuracy and recall of the model. The higher the accuracy and recall, the better the model. However, there is generally no positive correlation between accuracy and recall rate; that is, improving accuracy will usually reduce the recall rate, and improving the recall rate will reduce the accuracy of the model. In order to describe the prediction of the model on the consumption demand behavior of different types of agricultural products, the weighted harmonic calculation of the accuracy rate and recall rate of the model is adopted. The calculation results can comprehensively reflect the prediction results of the model on the consumption demand behavior of different types of agricultural products. The calculation formula is as follows:

$$
F_{1}=\frac{2 \times \operatorname{Pr} \times R e}{\operatorname{Pr}+R e} .
$$

In order to evaluate the performance of online agricultural product consumption demand analysis model, this paper designs the evaluation index of the model from the reference provided by the model for merchants to improve replenishment strategy and uses the model to analyze the factors affecting inventory goods. The merchant's inventory replenishment management mainly includes when to order and the order quantity. Generally, the main methods used in inventory replenishment include fixed replenishment quantity method, fixed time replenishment method, and the combination of fixed replenishment quantity and fixed time replenishment.

This paper constructs the prediction and analysis model of agricultural product consumption demand according to the classification of agricultural products to predict and analyze the online consumption demand behavior in a future cycle, so the model can be applied to replenish inventory regularly. As shown in Figure 6, the method of replenishing inventory at a fixed time indicates the maximum inventory, while S1, S2, S3, and S4, respectively, represent the inventory of agricultural products in different cycles. According to the inventory and maximum inventory of agricultural products in different periods, the inventory shortage of agricultural products in different periods can be obtained.

The online agricultural product consumption demand model established in this paper is based on the fixed time inventory replenishment method. Therefore, it is not affected by the maximum inventory quantity. The inventory 
TABLE 2: The error matrix used to describe the predicted value of the model and the actual statistical value.

\begin{tabular}{lcc}
\hline Actual statistical results & Model prediction results \\
& True & False \\
\hline True & TT & FT \\
False & TF & FF \\
\hline
\end{tabular}

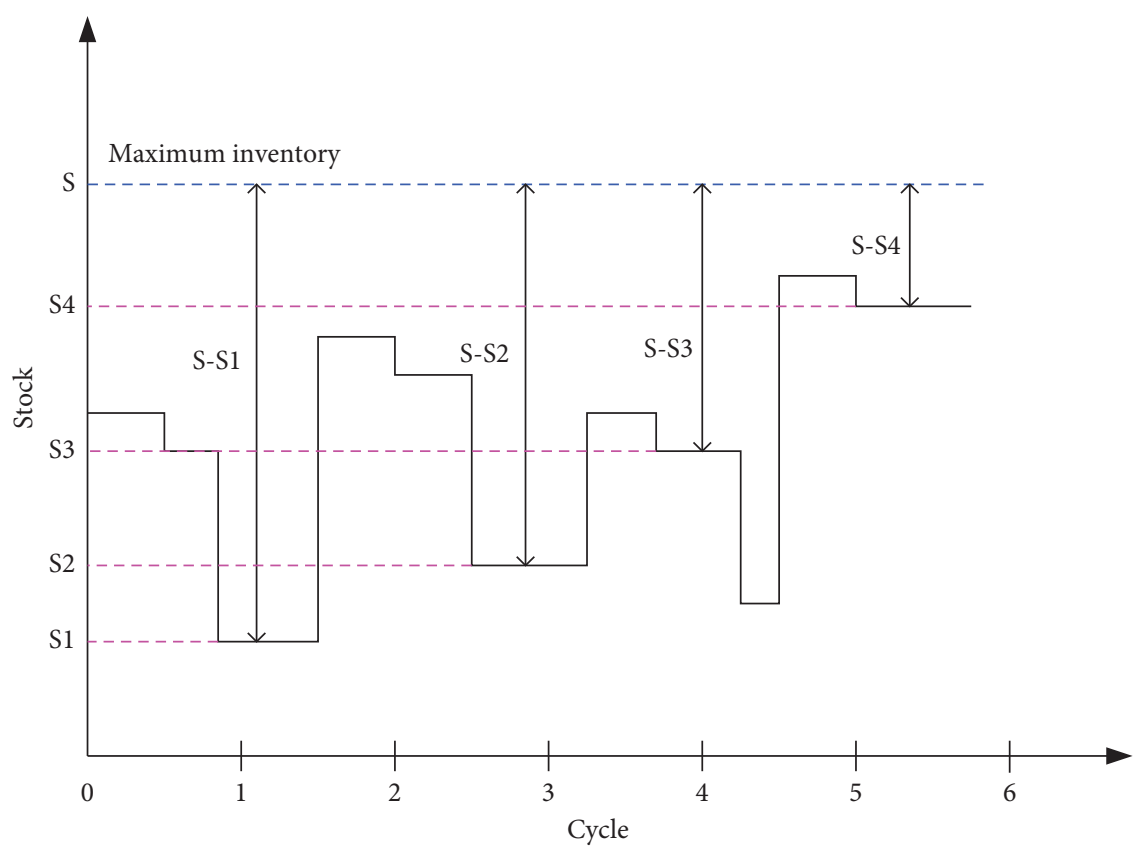

FiguRE 6: Schematic diagram of changes in replenishment of agricultural products over time.

replenishment quantity obtained from the consumption demand prediction model monitors the inventory quantity according to the fixed time cycle and thus predicts the required commodity replenishment quantity. Since the consumer demand prediction and analysis model is generally related to the model accuracy and commodity category when predicting and analyzing the consumer demand behavior of customers, there may be a certain deviation between the consumption demand quantity of agricultural products predicted by the model and the replenishment quantity of inventory commodities.

By collecting the actual sales volume and transaction price of several different types of agricultural products in each cycle, this paper uses the online agricultural product consumption demand model to predict the relevant parameters [20]. By comparing the actual sales volume and predicted value of agricultural products in each cycle, the inventory risk degree when using the consumption demand model to predict the consumption demand behavior of agricultural products can be calculated.

The consumption demand models of different types of agricultural products are used to predict the corresponding commodity consumption demand, and the predicted value is compared with the actual sales value to obtain the inventory replenishment quantity $[12,13]$. The calculation formula of inventory replenishment quantity is as follows:

$$
V_{M}^{T}=N_{A}^{T}-N_{P}^{T}
$$

where $N_{A}^{T}$ represents the actual consumption demand of online agricultural products in $T$ cycles, $N_{P}^{T}$ means the predicted demand of online agricultural product consumption in $T$ cycles obtained by using the model, and $V_{M}^{T}$ represents the difference between the predicted demand and actual sales of online agricultural products consumption in $T$ cycles obtained by the model, that is, the inventory shortage.

Using the consumption demand prediction model, we can predict the consumption quantity of different types of agricultural products in each cycle and take the predicted value of agricultural product consumption quantity as the inventory shortage in this cycle. For all different types of agricultural products, the total inventory shortage can be obtained, and its calculation formula is as follows:

$$
V^{T}=\sum_{i=1}^{T}\left(N_{A}^{i}-N_{P}^{i}\right) .
$$

If there are $m$ different types of agricultural products, the consumption demand prediction model can be used to predict the total inventory shortage of $m$ different types of agricultural products. The calculation formula is as follows:

$$
V=\sum_{j=1}^{m} \sum_{i=1}^{T}\left(N_{A}^{i}-N_{P}^{i}\right) .
$$


TABLE 3: Actual sales and forecast value of online consumption demand of rice in 8 weeks.

\begin{tabular}{lccccc}
\hline Week & Average sale price (dollar) & Actual sales $(\mathrm{kg})$ & Prediction value $(\mathrm{kg})$ & Stock-out $(\mathrm{kg})$ & Inventory shortage percentage \\
\hline 1 & 1.12 & 289 & 294 & 5 & 1.73 \\
2 & 1.07 & 367 & 358 & -9 & -2.45 \\
3 & 1.18 & 484 & 496 & 12 & 2.48 \\
4 & 1.14 & 493 & 512 & 19 & 3.85 \\
5 & 1.17 & 524 & 537 & -7 & 2.48 \\
6 & 1.13 & 486 & 479 & 11 & -1.44 \\
7 & 1.08 & 573 & 584 & 15 & 1.92 \\
8 & 1.15 & 548 & 563 & 2.74 \\
\hline
\end{tabular}

TABLE 4: Actual sales and forecast value of online consumption demand of egg in 8 weeks.

\begin{tabular}{lccccc}
\hline Week & Average sale price (dollar) & Actual sales $(\mathrm{kg})$ & Prediction value $(\mathrm{kg})$ & Stock-out $(\mathrm{kg})$ & Inventory shortage percentage \\
\hline 1 & 2.15 & 164 & 167 & 3 & 1.83 \\
2 & 2.24 & 177 & 183 & 6 & 3.39 \\
3 & 2.17 & 185 & 194 & 9 & 4.86 \\
4 & 2.34 & 237 & 228 & -9 & -3.80 \\
5 & 2.19 & 214 & 231 & -8 & -3.94 \\
6 & 2.36 & 206 & 198 & -5.56 \\
7 & 2.18 & 252 & 238 & -14 & 4.53 \\
8 & 2.27 & 243 & 254 & 11 & \\
\hline
\end{tabular}

TABLE 5: Actual sales and forecast value of online consumption demand of peanut in 8 weeks.

\begin{tabular}{lccccc}
\hline Week & Average sale price (dollar) & Actual sales $(\mathrm{kg})$ & Prediction value $(\mathrm{kg})$ & Stock-out $(\mathrm{kg})$ & Inventory shortage percentage \\
\hline 1 & 1.61 & 83 & 79 & -4 & -4.82 \\
2 & 1.47 & 112 & 108 & -4 & -3.57 \\
3 & 1.69 & 125 & 132 & 7 & 5.60 \\
4 & 1.74 & 134 & 143 & 9 & 6.72 \\
5 & 1.68 & 117 & 114 & -3 & -2.56 \\
6 & 1.74 & 132 & 147 & 15 \\
7 & 1.64 & 118 & 132 & 14 & -11.86 \\
8 & 1.59 & 125 & 106 & -19 & -15.20 \\
\hline
\end{tabular}

5.2. Results and Analysis. In order to compare the effects of online consumption demand forecasting models of different types of agricultural products on inventory shortage, in this paper, 50 similar products of three types of agricultural products are randomly selected from the test set samples for experiments, and the established consumer demand prediction model is used to predict the online sales of these three types of agricultural products in a total of 8 weeks from September 2020 to November 2020. As shown in Tables 3-5, the actual sales and forecast values of online consumption demand of rice, eggs, and peanuts within 8 weeks are compared in turn.

By comparing the predicted value of the model with the actual value, the total sales of three different agricultural products in eight cycles and the average weekly sales of similar agricultural products can be obtained. Therefore, according to the above relevant inventory shortage calculation formula, the respective inventory shortage volume and shortage rate of three different agricultural products can be obtained, as shown in Table 6. The comparison results of shortage indexes of different types of agricultural products are shown in Figure 7.
From the calculation and statistical results of inventory shortage and shortage rate, it is known that the sales volume predicted by the online consumption demand prediction model of similar agricultural products is close to the actual sales volume, and the difference between the predicted value of the model and the actual value of different types of agricultural products is different. Considering that there may be some differences in consumers' online consumption demand behavior for different types of agricultural products, there are also some differences in the consumption demand models constructed for different types of agricultural products. In addition, according to the statistical analysis results of inventory shortage risk in different types of agricultural product consumption demand models, the inventory shortage risk is closely related to the accuracy of the model. The higher the accuracy of the model, the smaller the shortage risk. Therefore, improving the prediction accuracy of agricultural product consumption demand model can not only reduce the risk of inventory shortage to a great extent, but also provide reference for the dynamic adjustment of inventory replenishment. 
TABLE 6: Comparison results of inventory shortage and inventory shortage rate of different agricultural products.

\begin{tabular}{lcr}
\hline Agricultural product & Average stock-out (kg) & Average inventory short percentage \\
\hline Rice & 59 & 1.41 \\
Egg & 15 & 1.16 \\
Peanut & 15 & 1.17 \\
\hline
\end{tabular}

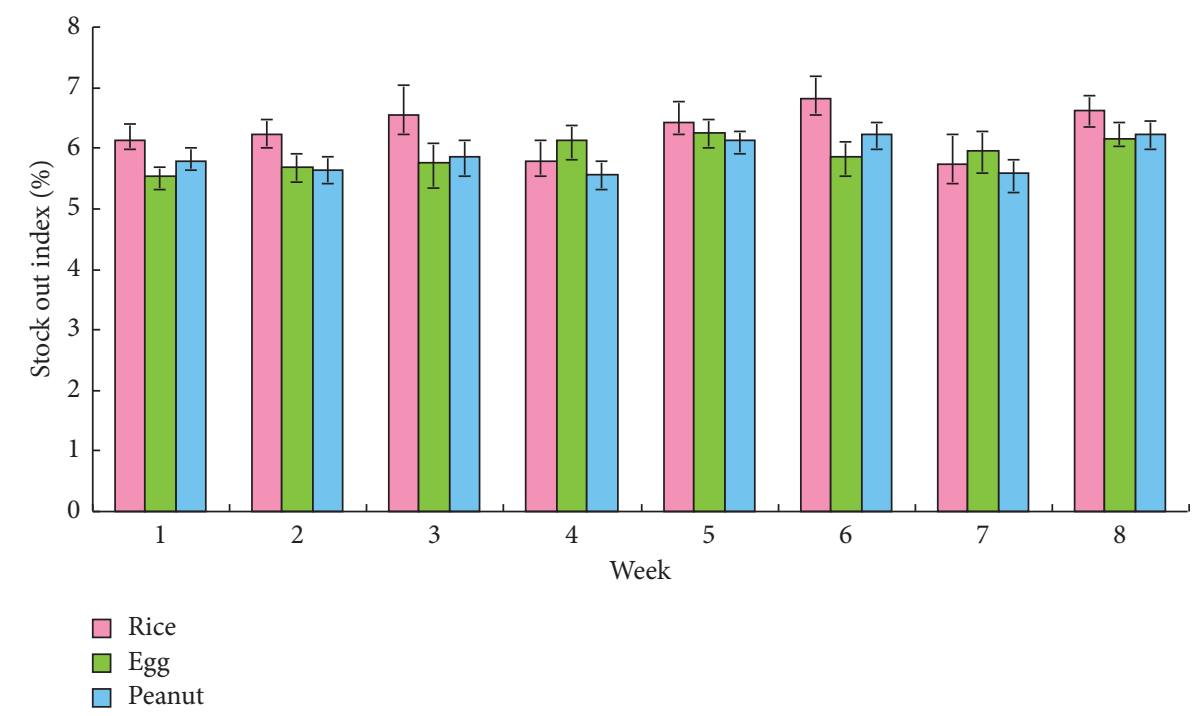

FIGURE 7: Comparison results of stock-out index of different types of agricultural products.

\section{Conclusion}

Based on the analysis of the relationship between agricultural and commercial enterprises and customers, this paper expounded customers and their consumption demand behavior for agricultural products and put forward the evaluation method of customers' consumption demand for agricultural products. The clustering method of data mining technology was used to classify the characteristics of consumer demand, and the mapping relationship between agricultural products and consumer demand was established. Finally, the online consumption demand forecasting and analysis model of agricultural products was proposed, and the performance of the demand forecasting model based on data classification was analyzed. The empirical application and analysis showed that the model proposed in this paper was feasible and effective. The model proposed in this paper not only helps to solve the problem of online agricultural product operation and service management, but also provides a reference for agricultural and commercial enterprises to deeply understand the potential consumer groups and their needs in the agricultural product market. Because there are many types of agricultural products, and customers' consumption behavior of online agricultural products may change with the change of the environment, it is necessary to continuously improve the consumption demand analysis model of online agricultural products in the future.

\section{Data Availability}

The labeled dataset used to support the findings of this study is available from the author upon request.

\section{Conflicts of Interest}

The author declares no conflicts of interest.

\section{References}

[1] M. Serkan Akturk, M. Ketzenberg, and G. R. Heim, “Assessing impacts of introducing ship-to-store service on sales and returns in omnichannel retailing: a data analytics study," Journal of Operations Management, vol. 61, no. 1, pp. 15-45, 2018.

[2] M. J. Ramirez, I. E. Roman, and I. E. Roman, “The value of supply chain integration in the Latin American agri-food industry: trust, commitment and performance out-comes," International Journal of Logistics ManageMent, vol. 32, no. 1, pp. 281-301, 2021.

[3] X. Meng, "Studying on construction programs of the platform of agricultural E-commerce," in Proceedings of the Workshop on Intelligent Information Technology Application (IITA 2007), pp. 354-357, Zhang Jiajia, China, 2009.

[4] L. Zhang and F. Zhu, "DQN based mobile edge computing for smart internet of vehicle," To Appear in EURASIP Journal on Advances in Signal Processing, vol. 99, pp. 1-10, 2022.

[5] J. Lu and M. Tang, "Analytical offloading design for mobile edge computing based smart internet of vehicle," To Appear in EURASIP Journal on Advances in Signal Processing, vol. 99, pp. 1-10, 2022.

[6] K. S. Baker and G. C. Bowker, "Information ecology: open system environment for data, memories, and knowing," Journal of Intelligent Information Systems, vol. 29, no. 1, pp. 127-144, 2007.

[7] W. Yu, R. Chavez, M. Jacobs, C. Y. Wong, and C. Yuan, "Environmental scanning, supply chain integration, 
responsiveness, and operational performance: an integrative framework from an organizational information processing theory perspective," International Journal of Operations \& Production ManAgement, vol. 39, no. 5, pp. 787-814, 2019.

[8] T. VaneIsIander, L. Deketele, and D. V. Hove, "Commonly used e-commerce supply chains for fast moving consumer goods: comparison and suggestion for improvement," International Journal of Logistics Research and Applications, vol. 16, no. 3, pp. 243-256, 2013.

[9] I. V. Kozlenkova, G. T. M. Hult, D. J. Lund, J. A. Mena, and P. Kekec, "The role of marketing channels in supply chain management," Journal of Retailing, vol. 91, no. 4, pp. 586-609, 2015.

[10] Q. Lu and N. Liu, "Effects of e-commerce channel entry in a two-echelon supply chain: a comparative analysis of single and dual channel distribution system," Int.J. Production Economics, vol. 165, pp. 100-111, 2015.

[11] S. Gallino, A. Moreno, and I. Stamatopoulos, "Channel integration, sales dispersion, and inventory management," Management Science, vol. 63, no. 9, pp. 2813-2831, 2017.

[12] H. Song, A. L. Tucker, and K. L. Murrell, "The diseconomies of queue pooling: an empirical investigation of emergency department length of stay," Management Science, vol. 61, no. 12, pp. 3032-3053, 2015.

[13] L. Cao and L. Li, "The impact of cross-channel integration on retailers' sales growth," Journal of Retailing, vol. 91, no. 2, pp. 198-216, 2015.

[14] G. Xu, B. Dan, X. Zhang, and C. Liu, "Coordinating a dualchannel supply chain with risk-averse under a two-way revenue sharing contract," International Journal of Production Economics, vol. 147, pp. 171-179, 2014.

[15] J. Avery, T. J. Steenburgh, J. Deighton, and M. Caravella, "Adding bricks to clicks: predicting the patterns of crosschannel elasticities over time," Journal of Marketing, vol. 76, no. 3, pp. 96-111, 2012.

[16] H. Christian, J. Vollmayr, and A. Hahn, "Firm value creation through major channel expansions: evidence from an event study in the United States, Germany, and China," Journal of Marketing, vol. 78, no. 3, pp. 38-61, 2014.

[17] S. Gold, N. Kunz, and G. Reiner, "Sustainable global agrifood supply chains: exploring the barriers," Journal of Industrial Ecology, vol. 21, no. 2, pp. 249-260, 2017.

[18] M. Kang, M. G. Yang, Y. Park, and B. Huo, "Supply chain integration and its impact on sustainability," Industrial Management and Data Systems, vol. 118, no. 9, pp. 1749-1765, 2018.

[19] C. Mora-Monge, G. Quesada, M. E. Gonzalez, and J. M. Davis, "Trust, power and supply chain integration in Web-enabled supply chains," Supply Chain Management: International Journal, vol. 24, no. 4, pp. 524-539, 2019.

[20] M. Jacobs, W. Yu, and R. Chavez, "The effect of internal communication and employee satisfaction on supply chain integration," International Journal of Production Economics, vol. 171, no. 1, pp. 60-70, 2016. 